\title{
Insights from insects about adaptive social information use
}

\author{
Christoph Grüter $^{1 *}, \dagger$ and Ellouise Leadbeater ${ }^{2 *}$ \\ ${ }^{1}$ Departamento de Biologia, Faculdade de Filosofia, Ciências e Letras de Ribeirão Preto, Universidade de São Paulo, \\ Av. Bandeirantes 3900, Ribeirão Preto, SP, Brazil \\ ${ }^{2}$ School of Biological Sciences, Royal Holloway University of London, Egham, Surrey TW20 0EX, UK
}

\begin{abstract}
Copying others can greatly improve individual fitness and is fundamental for the organisation of societies. Yet in some situations it is better to ignore social information and either explore the world individually or use personal information obtained through prior experience. Insects provide excellent models to study the strategic use of social information, but insights from recent research have rarely been viewed in the light of social learning strategies. Here we discuss how insects tailor their reliance on social information to those circumstances for which it is most beneficial, and suggest that insects and vertebrates use similar information-use strategies. We highlight future research avenues, including the use of molecular tools to study the genetic and genomic basis of social information use.
\end{abstract}

\section{Selective use of social information}

Animals are often faced with different types of information about their environment, and choosing the type that leads to the most successful behaviour is important but not straightforward [1-6]. Picture a woodland in which an ant forager is searching for honeydew sources. The ant can locate food in different ways: she can follow pheromone trails to new food sources discovered by others, look for new foraging sites herself, or choose to revisit food sources that she already knows about. In other words, she can acquire new information socially, acquire new information by individual exploration, or fall back on the personal information she has obtained, either individually or socially, through previous experience (cf. 'observe', 'innovate', and 'exploit' in [4]). Ants that rely on personal information will find an acceptable food site quickly because they already know its location, and trail followers might also be quicker than explorers. Yet if no ants explore, any new honeydew sources that arise are likely to go undiscovered while existing ones become depleted. Thus, despite potential time, energy, and predation risk costs, exploration could

\footnotetext{
Corresponding author: Grüter, C. (christoph.gruter@unil.ch).

*Both authors contributed equally to this work.

${ }^{\dagger}$ Current address: Department of Ecology and Evolution, Biophore, University of Lausanne, 1015 Lausanne, Switzerland.

0169-5347/\$ - see front matter

(c) 2014 Elsevier Ltd. All rights reserved. http://dx.doi.org/10.1016/j.tree.2014.01.004
}

improve individual and colony success when the environment changes.

Decisions like these are repeated throughout the animal kingdom whenever animals face a choice of whether or not to use social information. Social information might be 'cheap' to obtain, because individuals can bypass the costs and risks of exploration [3-5,7-11], and its quality is often assured because other animals tend to display the most profitable behaviours they know of $[4,12]$. However, the benefits of both social and personal information (trailfollowing or revisiting in our ant example) depend critically on the likelihood that resources change and on the behaviour of other individuals $[4,7,13]$. Clearly, animals should choose the option that will lead to the greatest payoffs in the context in which they find themselves, but how can they assess these potential payoffs in a complex and changing environment?

Here we discuss why insects provide tractable and varied model systems to study the adaptive use of social information in different contexts. We see that insect worlds involve both social environments and forms of social information that are rare or non-existent elsewhere and offer vast potential for experimental manipulation. For instance, in the social insects, social information use has

\footnotetext{
Glossary

Eusocial society: animal society characterised by reproductive division of labour between reproductive and (partially) sterile individuals. Brood care is cooperative and adult generations overlap (so adult workers might care for broods that are their siblings).

Exploration: gaining new information about the environment through individual sampling.

Personal information: information about the environment (e.g., the location of a feeding site) that an animal has acquired (either socially or asocially) and acted on previously.

Signal: trait such as a behaviour, or the products of a behaviour, that has been shaped by selection specifically because it conveys information from one animal to another. In the context of this article, we discuss signals that convey information about the environment, rather than about the motivation or qualities of the signaller.

(Coincidental) Social cue: trait such as a behaviour, or its products, that conveys information from one individual to another but has not evolved specifically for that function, such as the presence of an animal at a particular food site.

Social information: information about the environment that an animal acquires through observation or interaction with another animal or its products.

Social learning: learning about the environment that is influenced by interaction with, or observation of, another animal or its products. In the examples discussed in this review, social information use usually involves social learning. However, there are cases in which responding to social information might not necessarily involve learning, such as responses to alarm pheromones.
} 


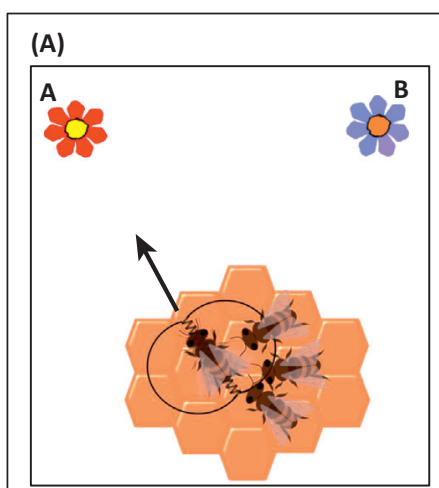

(B)

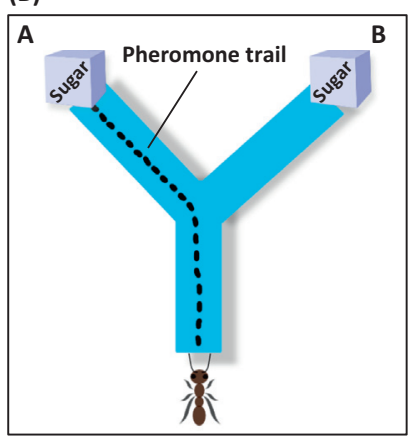

(C)

(D)

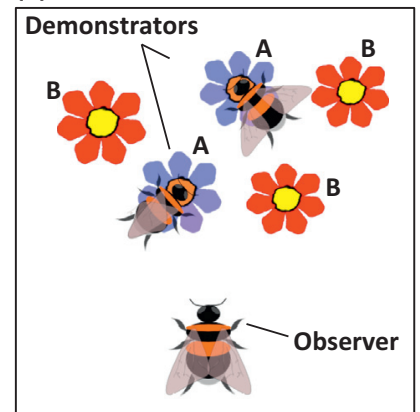

Demonstrator

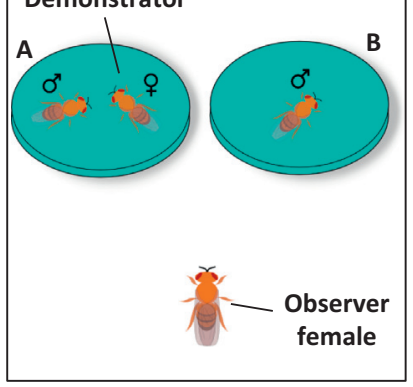

$\overline{T R E N D S}$ in Ecology \& Evolution

Figure 1. Experimental set-ups used to study social learning strategies in insects. (A) Honeybees [46,56], (B) ants [53,79], (C) bumblebees [68,80,81], and (D) fruit flies [18]. Insects face a choice between two options, A and B. Focal animals (observers) have social information about $A$ and either personal information or no prior information about B. The characteristics of social, personal, and asocial information can be manipulated, for example by increasing the distances of $A$ and $B$, varying the amount of experience of observers and demonstrators, and manipulating the time interval between exposure to information and testing of the observer. (A) Waggle dancing bee advertising food source $A$ and is surrounded by three observer bees. (B) Forager ant entering a $\mathrm{Y}$-maze that is marked by a pheromone trail leading to food source A. (C) Bumblebee observing bumblebee dummies on one of two flower types. (D) Fruit fly choosing one of two males, one of which is being chosen by a demonstrator female.

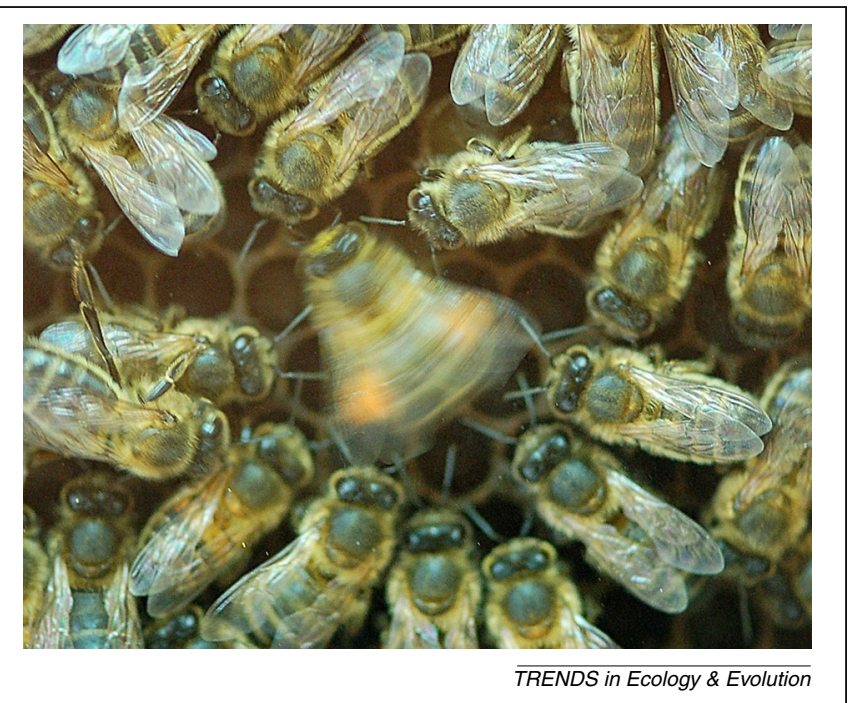

Figure 2. A honeybee pollen-forager performing a waggle dance and observer bees. She 'waggles' her abdomen as she walks in a straight line (waggle run), then turns to the left or right to walk back to the starting point (return phase). The better the food source, the more often she repeats the waggle run. The duration of the waggle run provides surrounding bees with information about the distance to the food source. The direction of the waggle run in relation to gravity provides information about the direction of the food source in relation to the sun [22]. The more waggle runs an observer bee follows, the better is her information about the location [90]. Dance followers learn not only of the food source but also its odour [91]. (Photo by C. Grüter.)

\section{Box 1. Social learning in insects}

In 1973, Karl von Frisch won the Nobel Prize for discovering that honeybees can communicate the location of a profitable resource by means of the waggle dance (see Figure 2 in the main text), but he and other authors before him built on a wealth of evidence that insects use social information. For example, by the time he discovered the 'dance language', he had already demonstrated that honeybees use the presence of other bees on flowers to identify food sources (local enhancement) and that bees learn food odours inside the nest while following dances and receiving food samples from foragers (social enhancement of food preferences) [22]. Both types of social learning have since been found in many other social insects: the scent and flavour of food collected by returning foragers and learned inside the nest guide foragers to rewarding flowers in bumblebees [82], stingless bees, wasps [17], and ants [83].

In the field, the foraging choices of many pollinators are further refined according to the presence of other foragers (wasps [84], bumblebees [80], stingless bees [17]) and chemical cues left by other foragers either inadvertently [17] or as evolved pheromone trails $[16,17]$. In some ant species, foragers actively guide nestmates to food sources or nest sites, a behaviour known as tandem running (http://www.youtube.com/watch?v=Kam0jKiAk3c) $[16,48,85]$. In several instances it has been shown that social insects use social cues or signals produced by heterospecifics, rather than their own species, to find food $[17,69]$. Most examples of social learning have been studied in the context of foraging, but bees, ants, and wasps also rely heavily on social information when hunting for new nest sites and during colony defence $[86,87]$.

Although the historical focus has been on eusocial species, more recent studies show that social learning guides important decisions in non-colonial insects and other invertebrates too [18-21,88,89]. Crickets and damselfly larvae use social cues to avoid predators $[23,89]$ and it has recently been shown that the fruit fly Drosophila melanogaster uses social information in a variety of contexts [1821 , such as when choosing oviposition substrates or mates (see Figure 1D in the main text).

often evolved into signalling, and these signals can easily be monitored, changed, or removed altogether. Moreover, it is possible to simulate ecology in the laboratory in a realistic manner while varying the costs and benefits of the different options (Figure 1). Insect social systems also incorporate variation in relatedness, providing the raw material to investigate the evolution of 'parasitic' social information-use strategies. Finally, insects provide genomically tractable models with short generation times to capitalise on the enormous potential offered by rapidly developing molecular technologies $[14,15]$.

Social information use in insects is widespread and diverse (Box 1) [16,17]. Although non-colonial insects such as the fruit fly Drosophila melanogaster have recently been established as potentially powerful social learning models [18-21], the greatest research effort has focused on the eusocial Hymenoptera [22,23], and the discovery of the honeybee waggle dance (Figure 2) is widely recognised as one of the most important developments in the study of animal behaviour (Box 1). Eusociality involves frequent social interaction and overlapping generations, favouring the evolution of social learning [24-26]. Individuals share mutual interests in colony success, so 'demonstrators' benefit from providing social information and coincidentally informative social cues have thus repeatedly evolved into signals through ritualisation and amplification $[16,27]$. Yet for this very reason, social insects are not traditionally discussed in the social learning literature, because responding to evolved signals rather than coincidental social cues 
(see Glossary) is not routinely classed as social learning [28] (but see $[23,25]$ ). However, the vast literature on the flexible responses of social insect to signals that convey information about the environment offers a valuable resource to better understand the interplay between the adaptive use of socially acquired information and animal ecology. In eusocial insects, the contexts in which animals choose to actively produce social information can be as informative as the contexts in which they choose to respond to it.

We first discuss the ultimate basis of flexible social information use, and how selection might have shaped behaviour accordingly. 'Social learning strategies' have become a promising research focus $[2-6,29-31]$ and there is increasing experimental support for such strategies in vertebrates, including humans [2-6,29-31]. We show that insects use social information strategically, when it is likely to be adaptive, irrespective of whether it is available as evolved signals or coincidental cues. Importantly, we consider situations when animals have the option to ignore social information (i.e., we do not discuss cases in which social information use is the only option). We then discuss the proximate means by which flexibility is achieved, focussing on evidence for associative learning of social cue value. Although social information-use strategies might sometimes derive from genetically inherited rules of thumb, there is now increasing evidence to suggest that they can be learnt $[28,32]$, and foraging insects are well suited for testing such hypotheses because their foraging experience can be closely controlled.

\section{The costs and benefits of social information use are highly variable}

We return briefly to our foraging ants searching for honeydew sources around their nest. An exploring ant might take a while to find food, but if food sources are abundant, such costs might be marginal. In honeybees, for example, the value of waggle dance information is sensitive to geographic location and season, presumably because these affect the availability and distribution of food [33-36]. Sometimes, time costs might even be higher for foragers that use dance information than for explorers, because they (i) need time to find dancers and (ii) often require several search trips to locate the advertised food source [37-39]. In general, the payoffs of social information use depend on many factors, including resource distribution $[36,40]$, the rate of environmental change $[4,7]$, the strategies of other individuals $[4,6,41]$, and predator abundance [42]. Even individual genotype can be important: in $D$. melanogaster, individuals with the naturally occurring for $^{\mathrm{S}}$ allele at the foraging locus are poorer at acquiring information through exploration, but are more likely to make use of social information compared to flies with the for $^{\mathrm{R}}$ allele [21]. Thus, the costs and benefits of relying on personal information, social information, and exploration are highly variable and context-specific, and none of the three options is systematically more adaptive. However, animals might be able follow simple behavioural rules that take advantage of general patterns regarding the costs and benefits of information [2-6,23].

One such pattern is that reliance on personal information, rather than acquisition of any new information, is often the best option [4]. It is commonly assumed that social information is 'cheap', because animals might avoid time and energy costs and mortality risks [3,7-10]. However, this presupposes that the alternative is exploration rather than personal information use, which by definition invokes no acquisition costs and thus is systematically cheaper still. For example, the honeybee waggle dance is a noisy signal [43-45] and observer bees often require multiple excursions to find the advertised food source [38]. A bee that returns to a known food source does not incur this cost, nor does it have to invest much time in extensive dance-following $[46,47]$. In the ant Temnothorax albipennis, foragers that return to known food sources are significantly quicker than ants that are led there by tandem leaders (Box 1) [48]. Correspondingly, in a large-scale simulation study, players that typically relied heavily on information that they had already acquired (played 'exploit') significantly outperformed those that more often played 'innovated' (explored) or 'observed' (acquired social information) strategies [4].

If the environment changes, however, a need to acquire new information arises because personal information might no longer provide rewards [4,7], potentially tipping the balance in favour of social information use or exploration [49]. Exploration might produce more up-to-date information, as we have already discussed, but social information might be just as current if sufficient 'demonstrators' are exploring [41]. Social information might be generally more profitable than exploration, because other animals tend to display the most profitable behaviours that they know [4]. For example, honeybees will not advertise foraging sites by dancing when returning from every food source, but only when the foraging patch provides excellent rewards $[22,50]$. As a result, sites found by following waggle dances are typically of higher quality than those found by exploration [38]. Social learning strategies which might be genetically determined responses to environmental and social cues, or the result of learning about the payoffs of copying - provide a means by which animals might judge the context that they are in and respond adaptively.

\section{Social learning strategies in insects}

Social learning or social information-use strategies determine under which circumstances individuals use social information and enable them to use social information when it is likely to be the best option. For example, the strategy 'copy if dissatisfied' [3], whereby animals use social information if their current behaviour is below a threshold reward level, is a proximate means to use social information if private information is not very productive. There is increasing evidence of social learning strategies in vertebrates [2,3,5,6,29-31], but do insects use similar strategies? We follow previous authors in distinguishing between 'when to copy' and 'who to copy' strategies (Box 2) $[2,3,5,24,29]$.

\section{'When' strategies}

A frequently discussed 'when' strategy that emphasises the costs of exploration $[3,7,8,29,51]$ is 'copy if asocial information is costly'. There is evidence that black garden ants 


\section{Box 2. Social learning strategies in animals}

Various possible social learning strategies have been proposed [2,3,5,6,31]. Below is a non-exhaustive list of 'when to copy' and 'who to copy' strategies. We highlight vertebrate and insect studies that provide evidence of different strategies. In some cases, evidence is not unequivocal $[2,3]$. Some of the strategies are not discussed in the main text, such as the 'copy kin' strategy and the 'copy older individuals' strategy even though both are likely to exist in social insects owing to high worker-worker relatedness and overlapping generations.

\section{'When' strategies}

- Copy if asocial information (exploration) is costly

- Copy if personal information is costly

- Copy if dissatisfied

- Copy if personal information is unreliable

- Copy if personal information is outdated

- Copy if uncertain

'Who' strategies

- Copy the majority

- Copy successful individuals

- Copy if better

- Copy older individuals

\section{Vertebrate examples}

Fish [2,3,5], starlings [6], humans [31]

Fish [42]

Rats [92], humans [31]

Fish $[2,3,5]$

Fish $[3,5]$

Fish [3,5], rats [92], humans [31]

Fish [5], humans [31]

Fish [3], bats [3], chimpanzees [5]

Sticklebacks [2], humans [31]

Chimpanzees [5], fish [5]
Insect examples Bumblebees [54] Honeybees [55] Honeybees [56]

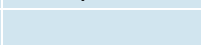

(Lasius niger) foraging in a maze (Figure 1) pay more attention to pheromone trail information for route choices when the route is difficult to learn and so time costs of exploration are high [52], than when the route is easy to learn [53]. Likewise, bumblebees (Bombus impatiens) rely more heavily on conspecific scent cues to identify recently drained flowers when floral morphology means that sampling of a flower alone requires more time [54].

A closely related strategy, but one that focuses on the use of personal information as the alternative to social information use, is the 'copy if dissatisfied' strategy $[2,3,5,29]$. This strategy is simpler mechanistically, because it does not require animals to compare or evaluate alternative options [3], but rather to assess its satisfaction in relation to some internal threshold. For example, Wray and colleagues trained honeybees to feeders at either $100 \mathrm{~m}$ or $1000 \mathrm{~m}$, and found that the latter group were subsequently more likely to use the social information provided by waggle dancers advertising a new food source (Figure 1A) [55]. When Grüter et al. increased the costs of using personal information as in [55], but provided aboveaverage rewards associated with personal information use, foragers were not enticed to switch to social learning: more bees preferred to visit a known food source than a much closer, equally rewarding one that they had social information about [56]. Because bees followed these dances extensively, they had access to information about both locations and could potentially have compared the flight costs of the two options. The fact that they preferred the familiar feeder despite the greater energetic costs is consistent with a 'copy if dissatisfied' strategy [56].

There are several other possible 'when' strategies, such as 'copy if uncertain' and 'copy if personal information is outdated', but for many of them empirical evidence is still limited or absent (Box 2). However, it has been shown that cactus bugs (Chelinidae vittiger) respond to the recency of (social) information. When conspecific nymphs are present on breeding substrates, individuals increase egg production, but when nymphs have previously been observed on the substrate but have since disappeared (perhaps indicating predation), their presence has little effect [57]. The presence of nymphs can be highly valuable information because it demonstrates that offspring have hatched and survived on the substrate. Another recent study suggests that ants respond to the reliability of personal information: L. niger foragers travelling between a food source and their nest increase their pheromone-laying if they previously made a mistake when trying to locate the food source [52]. In other words, signallers assess when recipients would do well to use social information, and adjust their behaviour accordingly. Thus, signallers might employ information provision strategies that reflect the benefits of social information use to recipients. Although exploring (and thus providing information) might invoke individual costs, in cooperative groups, providing information benefits all, so exploration might be more common than otherwise expected (see below). Clearly, more research is needed to explore the role of 'when' strategies in insect decisionmaking.

\section{'Who' strategies}

The identity and characteristics of potential demonstrators can also critically influence the value of social information $[2,3,5,7,9,24,29,51]$. One possible strategy is to 'copy the majority'. More precisely, the probability of acquiring a behaviour socially might increase disproportionately with the proportion of other animals performing the same behaviour [3,5,9,58]. Copying the majority (or 'conformity bias') could be adaptive if majority behaviour indicates the most successful behavioural variant. Naïve ants reaching a trail bifurcation (Figure 1B) can indirectly evaluate the relative proportion of other ants choosing one of the two branches by estimating the amount of pheromone on each branch [59]. Naiive foragers often disproportionately prefer the branch marked with more pheromone (non-linear positive feedback), leading to a strong collective bias even if the two resources are identical in quality [59,60]. This can help groups to monopolise food sources in a competitive environment [59], but it can also cause colonies to become trapped in suboptimal situations: colonies of some pheromone-laying ant and bee species show a reduced ability to switch to superior food sources that are discovered after foraging at a mediocre food source is already under way [59-61]. Accordingly, there is ongoing discussion about the 
conditions that favour 'copy the majority' and whether these are commonly found in nature $[2,5,58]$.

Animals might identify successful individuals and preferentially learn from them $[2,3,5,9,29]$. A 'copy successful individuals' strategy requires only the ability to identify individuals that are currently successful, for example by monitoring payoffs, rather than individual recognition [3]. Female fruit flies appear to use this strategy when choosing an egg-laying substrate. Females socially learn about suitable egg-laying substrates by observing other females on substrates, but only mated females with eggs are copied, and not virgin flies [19].

So far we have focused on situations in which individuals have to choose between two options, such as social and personal information (Figure 1). However, there will naturally be situations for which personal and social information is in agreement and individuals might be able to use both types of information in combination to act more efficiently [6]. In the ant $L$. niger, there is no difference in walking speed between ants using route memory alone and those following a pheromone trail when travelling between the nest and a food source. However, if foragers with route memory simultaneously perceive a pheromone trail on their way, they are able to walk with increased speed, demonstrating a synergistic effect of the two information sources [62].

\section{Cooperative social learning strategies}

When direct interaction with the environment is risky or time-consuming, animals that explore (information 'producers') incur costs that social information users ('scroungers') avoid $[3,10,13]$. In eusocial societies and other cooperative groups, however, individual fitness is tightly linked to group success [16], so the producer-scrounger distinction is less meaningful. Instead, we would expect animals to sacrifice individual foraging success to improve group success, and thus their own indirect fitness, in circumstances where the two conflict.

There is evidence of cooperative social learning strategies in social insects. A particular type of honeybee forager, the scout, represents approximately $5-30 \%$ of the foragers in a colony $[15,50]$. Scouts are consistent information producers: even after finding a profitable food source to which they recruit other workers, they often abandon these to find new ones [15]. This is unlikely to maximise individual success, which makes it an intriguing foraging strategy. Scouts are characterised by particular gene expression patterns in the brain: approximately $16 \%$ of the genes studied by Liang et al. were differentially expressed in the brains of scouting bees compared to foragers that relied on social learning to find a food source [15]. Interestingly, some of the differentially expressed genes are linked to novelty-seeking behaviour in vertebrates [15]. Thus, scouts are explorers that help the colony to keep track of changes and discover new foraging opportunities or nest sites $[15,50]$. Several unexplored questions arise from these findings, such as whether the frequency of scouts in a colony differs between populations in different environments, whether colony-level variation in scout proportions has a genetic component, and whether there is an optimal proportion of scouts for colony fitness that varies with the environment. Another question is whether there are evolutionarily conserved molecular mechanisms underlying consistent differences in the propensity to explore, copy, or use personal information. If so, the same genes might be involved in causing copying behaviour in different species.

Laland has argued that because of kin selection the probability of social learning should correlate positively with relatedness between the observer and demonstrator [3]. However, the previous example shows that shared interests can also lead to less frequent social learning when group success depends on the group ability to discover new food sources. In other words, high relatedness could produce lower frequencies of social learning when exploration is important for group success. In the stingless bee Tetragonisca angustula, for example, worker-worker relatedness is considerably higher than in Apis mellifera honeybees [63], yet its foraging behaviour is among the most solitary of the stingless bee species [64].

\section{The proximate basis for flexibility}

We have outlined why social information use should ultimately be strategic. Is this context specificity genetically encoded, representing an evolutionary adaptation for social life? An alternative suggestion is that animals learn about the payoffs of social information use through experience, and thus modify their behaviour accordingly. Several vertebrate studies give reason to suggest that strategies can arise through learning. For example, Dolman and colleagues provide evidence that Zenaida doves (Zenaida aurita) learn whether to copy conspecifics or heterospecifics when making foraging decisions [65]. In humans, 5year-old children tend to use social information from familiar over unfamiliar teachers, but quickly switch to the unfamiliar teacher on discovering that he or she is more reliable [66]. Such studies imply that strategies for social information use are shaped by learning, but there are other explanations. To unequivocally demonstrate that experience shapes social information use, it is necessary to compare individuals whose experience can be closely controlled.

Social insect systems are particularly well suited to this task, because individual experience is relatively straightforward to manipulate in the laboratory and even in the field. For example, naïve bumblebees that have never previously foraged outside the nest show very weak preferences for flowers where other bumblebees are present $[67,68]$, but in experienced foragers preferences for occupied flowers become robust if the presence of conspecifics has reliably predicted rewards in the past [68]. If, however, honeybee demonstrators provide more useful information, bumblebees will learn to join honeybees instead [69]. Stingless bees also learn about who to copy. Some species follow trail pheromones to food resources, and bees can distinguish between trails belonging to their own colony and those of others [17]. Cross-fostered bees of two Scaptotrigona species prefer foster-colony trails [70], implying that such biases arise through learning. There is also evidence to suggest that tandem-running ants become better tandem leaders through experience [71]; it would be interesting to investigate whether followers also learn to select more experienced individuals to follow. 
Evidence is also accumulating that individuals learn 'when' to use social information, producing behaviour that is closely matched to local environmental conditions. For example, Dawson and colleagues recently showed that observational learning in bumblebees arises through a second-order conditioning process, and thus only occurs when conspecifics provide useful information [72]. When conspecifics are not reliably associated with reward, bees do not prefer flower colours where they have seen others forage; in fact, in this study they could even be trained to avoid popular flower colours when this proved more rewarding. Likewise, bees learn to use conspecific and heterospecific chemical 'footprints' to avoid recently drained flowers only when they forage on flowers where such marks are useful; when the marks are found on rewarding flowers, they become attractive [73,74].

Together, these results are beginning to suggest that strategic use of social information might often reflect associative learning rather than unlearnt rules of thumb [32]. Even action imitation, a copying mechanism long considered an adaptation to social life, may be a byproduct of the ability to learn rather than an evolutionary adaptation $[28,75]$. It seems likely that use of context-specific social information might often reflect a combination of unlearnt biases that allow naïve individuals a head start in producing generally adaptive behaviour, and learning that tunes such biases to match local conditions. To tease apart these two mechanisms, we need to look more closely at social information use in naïve individuals who have had limited opportunity to learn about social cue value $[68,72,76]$.

Another outstanding question in both vertebrates and invertebrates is whether animals learn rules that can be generalised across contexts. For example, if an animal learns to copy the majority when searching for rewarding food sources, does it also copy the majority when choosing an escape route? Empirical investigation of the ontogeny of social information use is necessary if we are to understand what actually evolves during the evolution of social learning $[5,32]$.

\section{Concluding remarks}

It is becoming clear that adaptive use of social information does not require large brains, but can be achieved through rather simple social learning strategies, which might be inherited genetically or might arise through learning. It appears that insects and vertebrates, including humans, use similar rules when deciding whether to copy others (Box 2), which suggests that information use strategies are more likely to reflect ecological selection pressures than brain size or phylogenetic relationships [5]. We identify three areas in which we feel that insects can make a timely contribution (Box 3). (i) Linking social information use to fitness. (ii) Disentangling memory and exploration: most theoretical treatments and empirical studies lump memory and exploration together as 'asocial learning' (but see $[4,5])$, but the two have very different costs (e.g., in acquisition) and benefits (e.g., obtaining up-to-date information). (iii) One of the most timely contributions that insect studies can offer derives from their popularity as genetic and genomic models. The abundance of genomic information available for the honeybee [77] and fruit fly [78] make them

\section{Box 3. Future research areas}

- Linking social information use to fitness. Honeybee studies have taken first steps towards addressing this link. Sherman and Visscher found that experimentally preventing honeybees from using dance information only reduced colony food intake in the Californian winter, but not spring or summer [35]. Dornhaus and Chittka showed that the same manipulation was effective in certain tropical but not temperate habitats [34]. Both groups relate their findings to habitat structure, suggesting that recruitment is most important when resources are clumped or ephemeral, paving the way for studies that use similar techniques but specifically manipulate environmental conditions. Insect systems lend themselves to such manipulations: honeybee dances can be rendered meaningless by placing hives horizontally, and stingless bee and ant pheromone trails can be removed. Investigating the effects of making social information useless while controlling environmental structure [33] is a promising and yet underutilised avenue for future research.

- Disentangling personal information use and exploration. Throughout this review we presented the options facing decision-makers as threefold: rely on personal information, acquire new information socially, or acquire new information through exploration. To distinguish between these options, animals should be offered the choice between resources that they have already sampled (irrespective of whether they were originally discovered through social information use or exploration), resources indicated socially, and unknown options. Honeybee and ant systems, for which food resources and signals can be manipulated, might be good models for this task.

- Understanding the molecular basis of social information use. Insect studies can offer insights into the molecular basis of social information use, through to their popularity as genetic and genomic models. New work is already beginning to make use of the rapidly developing resources $[15,21,93,94]$. This can help us understand how environment and individual experience affect information use via changes in gene expression and whether there are evolutionarily conserved mechanisms that regulate social information use in taxonomically diverse species. Molecular tools can elucidate the steps that are required for social learning to evolve from other behaviours, such as the tendency or motivation to aggregate [21]. Furthermore, if the reliance on personal information, social information, or exploration is characterised by particular brain gene expression patterns [15], then genomic tools could be used to monitor the frequency and dynamics of behavioural strategies without the need to observe behaviours, both on a population level (e.g., recognising honeybee scouts) and within individuals (e.g., looking at gene expression changes that occur when honeybees follow dances).

ideal models to study the molecular basis of social information use.

\section{Acknowledgements}

We are grateful to Nicolas Châline, Tomer Czaczkes, Nichola Raihani, and Francisca Segers for comments on earlier drafts, and to Luke Rendell and an anonymous referee for comments on the manuscript. C.G. is funded by a Science Without Borders Fellowship from the Brazilian National Council for Scientific and Technological Development (CNPq, process number 400664/2012-7). E.L. is funded by a Leverhulme Trust Early Career Fellowship.

\section{References}

1 Dall, S.R.X. et al. (2005) Information and its use by animals in evolutionary ecology. Trends Ecol. Evol. 20, 187-193

2 Kendal, R.L. et al. (2009) Adaptive trade-offs in the use of social and personal information. In Cognitive Ecology II (2nd edn) (Dukas, R. and Ratcliffe, J.M., eds), pp. 249-271, University of Chicago Press

3 Laland, K.N. (2004) Social learning strategies. Learn. Behav. 32, 4-14 
4 Rendell, L. et al. (2010) Why copy others? Insights from the social learning strategies tournament. Science 328, 208-213

5 Rendell, L. et al. (2011) Cognitive culture: theoretical and empirical insights into social learning strategies. Trends Cogn. Sci. 15, 68-76

6 Rieucau, G. and Giraldeau, L.A. (2011) Exploring the costs and benefits of social information use: an appraisal of current experimental evidence. Philos. Trans. R. Soc. B 366, 949-957

7 Boyd, R. and Richerson, P.J. (1985) Culture and the Evolutionary Process, University of Chicago Press

8 Feldman, M.W. et al. (1996) Individual versus social learning: evolutionary analysis in a fluctuating environment. Anthropol. Sci. 104, 209-213

9 Henrich, J. and McElreath, R. (2003) The evolution of cultural evolution. Evol. Anthropol. 12, 123-135

10 Kameda, T. and Nakanishi, D. (2002) Cost-benefit analysis of social/ cultural learning in a nonstationary uncertain environment: an evolutionary simulation and an experiment with human subjects. Evol. Hum. Behav. 24, 242-260

11 Enquist, M. et al. (2007) Critical social learning: a solution to Rogers's paradox of nonadaptive culture. Am. Anthropol. 109, 727-734

12 Grüter, C. et al. (2010) Social learning: the importance of copying others. Curr. Biol. 20, R683-R685

13 Giraldeau, L.A. et al. (2002) Potential disadvantages of using socially acquired information. Philos. Trans. R. Soc. B 357, 1559-1566

14 Bell, A.M. and Robinson, G.E. (2011) Behavior and the dynamic genome. Science 332, 1161-1162

15 Liang, Z.S. et al. (2012) Molecular determinants of scouting behavior in honey bees. Science 335, 1225-1228

16 Hölldobler, B. and Wilson, E.O. (2009) The Superorganism: The Beauty, Elegance, and Strangeness of Insect Societies, W.W. Norton \& Company

17 Jarau, S. and Hrncir, M. (2009) Food Exploitation by Social Insects: Ecological, Behavioral, and Theoretical Approaches, CRC Press

18 Mery, F. et al. (2009) Public versus personal information for mate copying in an invertebrate. Curr. Biol. 19, 730-734

19 Sarin, S. and Dukas, R. (2009) Social learning about egg-laying substrates in fruitflies. Proc. R. Soc. B 276, 4323-4328

20 Battesti, M. et al. (2012) Spread of social information and dynamics of social transmission within Drosophila groups. Curr. Biol. 22, 309-313

21 Foucaud, J. et al. (2013) A genetic polymorphism affecting reliance on personal versus public information in a spatial learning task in Drosophila melanogaster. Proc. R. Soc. B 280, 20130588

22 von Frisch, K. (1967) The Dance Language and Orientation of Bees, Harvard University Press

23 Leadbeater, E. and Chittka, L. (2007) Social learning in insects - from miniature brains to consensus building. Curr. Biol. 17, R703-R713

24 Coussi-Korbel, S. and Fragaszy, D.M. (1995) On the relation between social dynamics and social learning. Anim. Behav. 50, 1441-1453

25 Hoppitt, W. and Laland, K.N. (2008) Social processes influencing learning in animals: a review of the evidence. Adv. Stud. Behav. 38, $105-165$

26 Thornton, A. and Raihani, N.J. (2008) The evolution of teaching. Trends Ecol. Evol. 75, 1823-1836

27 Tinbergen, N. (1952) 'Derived' activities, their causation, biological significance and emancipation during evolution. Q. Rev. Biol. 27, 1-32

28 Heyes, C.M. (2012) What's social about social learning. J. Comp. Psychol. 126, 193-202

29 Kendal, R.L. et al. (2005) Trade-offs in the adaptive use of social and asocial learning. Adv. Stud. Behav. 35, 333-379

30 Mesoudi, A. (2011) An experimental comparison of human social learning strategies: payoff-biased social learning is adaptive but underused. Evol. Hum. Behav. 32, 334-342

31 Morgan, T.J.H. et al. (2012) The evolutionary basis of human social learning. Proc. R. Soc. B 279, 653-662

32 Reader, S. (2013) Experimental effects on mirror systems and social learning: implications for social intelligence. Behav. Brain Sci. (in press)

33 Donaldson-Matasci, M.C. and Dornhaus, A. (2012) How habitat affects the benefits of communication in collectively foraging honey bees. Behav. Ecol. Sociobiol. 66, 583-592

34 Dornhaus, A. and Chittka, L. (2004) Why do honey bees dance? Behav. Ecol. Sociobiol. 55, 395-401

35 Sherman, G. and Visscher, P.K. (2002) Honeybee colonies achieve fitness through dancing. Nature 419, 920-922
36 Beekman, M. and Lew, J.B. (2008) Foraging in honeybees - when does it pay to dance? Behav. Ecol. 19, 255-262

37 Seeley, T.D. (1983) Division of labor between scouts and recruits in honeybee foraging. Behav. Ecol. Sociobiol. 12, 253-259

38 Seeley, T.D. and Visscher, P.K. (1988) Assessing the benefits of cooperation in honeybee foraging: search costs, forage quality, and competitive ability. Behav. Ecol. Sociobiol. 22, 229-237

39 Dechaume-Moncharmont, F.X. et al. (2005) The hidden cost of information in collective foraging. Proc. R. Soc. B 272, 1689-1695

40 Dornhaus, A. et al. (2006) Benefits of recruitment in honey bees: effects of ecology and colony size in an individual-based model. Behav. Ecol. 17, 336-344

41 Rogers, A.R. (1988) Does biology constrain culture? Am. Anthropol. 90, 819-831

42 Webster, M.M. and Laland, K.N. (2008) Social learning strategies and predation risk: minnows copy only when using private information would be costly. Proc. R. Soc. B 275, 2869-2876

$43 \mathrm{Al}$ Toufailia, H.M. et al. (2013) Honey bee waggle dance communication: signal meaning and signal noise affect dance follower behaviour. Behav. Ecol. Sociobiol. 67, 549-556

44 Couvillon, M.J. et al. (2012) Working against gravity: horizontal honeybee waggle runs have greater angular scatter than vertical waggle runs. Biol. Lett. 8, 540-543

45 Tanner, D.A. and Visscher, P.K. (2010) Adaptation or constraint? Reference-dependent scatter in honey bee dances. Behav. Ecol. Sociobiol. 64, 1081-1086

46 Grüter, C. et al. (2008) Informational conflicts created by the waggle dance. Proc. R. Soc. B 275, 1321-1327

47 Grüter, C. and Farina, W.M. (2009) The honeybee waggle dance: can we follow the steps? Trends Ecol. Evol. 24, 242-247

48 Franks, N.R. and Richardson, T. (2006) Teaching in tandem-running ants. Nature 439, 153

49 Grüter, C. and Ratnieks, F.L.W. (2011) Honeybee foragers increase the use of waggle dance information when private information becomes unrewarding. Anim. Behav. 81, 949-954

50 Seeley, T.D. (1995) The Wisdom of the Hive: The Social Physiology of Honey Bee Colonies, Harvard University Press

51 Boyd, R. and Richerson, P.J. (1995) Why does culture increase human adaptability? Ethol. Sociobiol. 16, 125-143

52 Czaczkes, T.J. et al. (2013) Ant foraging on complex trails: route learning and the role of trail pheromones in Lasius niger. J. Exp. Biol. 216, 188-197

53 Grüter, C. et al. (2011) Decision-making in ant foragers (Lasius niger) facing conflicting private and social information. Behav. Ecol. Sociobiol. 65, 141-148

54 Saleh, N. et al. (2006) Facultative use of the repellent scent mark in foraging bumblebees: complex versus simple flowers. Anim. Behav. 71, 847-854

55 Wray, M.K. et al. (2012) Honey bees use social information in waggle dances more fully when foraging errors are more costly. Behav. Ecol. $23,125-131$

56 Grüter, C. et al. (2013) Social learning strategies in honeybee foragers: do the costs of using private information affect the use of social information? Anim. Behav. 85, 1443-1449

57 Fletcher, R.J. and Miller, C.W. (2008) The type and timing of social information alters offspring production. Biol. Lett. 4, 482-485

58 Eriksson, K. et al. (2007) Critical points in current theory of conformist social learning. J. Evol. Psychol. 5, 67-87

59 Detrain, C. and Deneubourg, J-L. (2008) Collective decision-making and foraging patterns in ants and honeybees. Adv. Insect Physiol. 35, $123-173$

60 Sumpter, D.J.T. (2010) Collective Animal Behavior, Princeton University Press

61 Schmidt, V.M. et al. (2006) Collective foraging in a stingless bee: dependence on food profitability and sequence of discovery. Anim. Behav. 72, 1309-1317

62 Czaczkes, T.J. et al. (2011) Synergy between social and private information increases foraging efficiency in ants. Biol. Lett. 7, 521-524

63 Strassmann, J. (2001) The rarity of multiple mating by females in the social Hymenoptera. Insectes Soc. 48, 1-13

64 Hrncir, M. and Maia-Silva, C. (2013) On the diversity of forging-related traits in stingless bees. In Pot-Honey: A legacy of stingless bees (Vit, P. et al., eds), pp. 201-215, Springer 
65 Dolman, C.S. et al. (1996) Mode of foraging competition is related to tutor preference in Zenaida aurita. J. Comp. Psychol. 110, 45-54

66 Harris, P.L. and Corriveau, K.H. (2011) Young children's selective trust in informants. Philos.Trans. R. Soc. Lond. B 366, 1179-1187

67 Kawaguchi, L.G. et al. (2006) Do bumble bees save time when choosing novel flowers by following conspecifics? Funct. Ecol. 20, 239-244

68 Leadbeater, E. and Chittka, L. (2009) Bumble-bees learn the value of social cues through experience. Biol. Lett. 5, 310-312

69 Dawson, E.H. and Chittka, L. (2012) Conspecific and heterospecific information use in bumblebees. PLoS ONE 7, e31444

70 Reichle, C. et al. (2013) Learnt information in species-specific 'trail pheromone' communication in stingless bees. Anim. Behav. 85, 225232

71 Franklin, E.L. et al. (2012) Do ants need to be old and experienced to teach? J. Exp. Biol. 215, 1287-1292

72 Dawson, E.H. et al. (2013) Learning by observation emerges from simple associations in an insect model. Curr. Biol. 23, 1-4

73 Saleh, N. and Chittka, L. (2006) The importance of experience in the interpretation of conspecific chemicals signals. Behav. Ecol. Sociobiol. $61,215-220$

74 Sanchez, D. et al. (2008) Experience-based interpretation of visual and chemical information at food sources in the stingless bee Scaptotrigona mexicana. Anim. Behav. 76, 407-414

75 Cook, R. et al. (2013) Mirror neurons: from origin to function. Behav. Brain Sci. (in press)

76 Leadbeater, E. and Chittka, L. (2011) Do inexperienced bumblebee foragers use scent marks as social information? Anim. Cogn. 14, 915919

77 Weinstock, G.M. et al. (2006) Insights into social insects from the genome of the honeybee Apis mellifera. Nature 443, 931-949

78 Adams, M.D. et al. (2000) The genome sequence of Drosophila melanogaster. Science 287, 2185-2195

79 Elizalde, L. and Farji-Brener, A.G. (2012) To be or not to be faithful: flexible fidelity to foraging trails in the leaf-cutting ant Acromyrmex lobicornis. Ecol. Entomol. 37, 370-376
80 Leadbeater, E. and Chittka, L. (2005) A new mode of information transfer in bumblebees? Curr. Biol. 15, R447-R448

81 Worden, B.D. and Papaj, D. (2005) Flower choice copying in bumblebees. Biol. Lett. 1, 504-507

82 Dornhaus, A. and Chittka, L. (1999) Evolutionary origins of bee dances. Nature 401, 38

83 Provecho, Y. and Josens, R. (2009) Olfactory memory established during trophallaxis affects food search behaviour in ants. J. Exp. Biol. 212, 3221-3227

84 Hrncir, M. et al. (2007) Exploitation of carbohydrate food sources in Polybia occidentalis: social cues influence foraging decisions in swarmfounding wasps. Behav. Ecol. Sociobiol. 61, 975-983

85 Gottlieb, D. et al. (2013) Individual and social information gathering are fine-tuned to the internal state of the group. Anim. Behav. 85, 1479-1484

86 Seeley, T.D. (2010) Honeybee Democracy, Princeton University Press

87 Stroeymeyt, N. et al. (2011) Knowledgeable individuals lead collective decisions in ants. J. Exp. Biol. 214, 3046-3054

88 Webster, S.J. and Fiorito, G. (2001) Socially guided behaviour in noninsect invertebrates. Anim. Cogn. 4, 69-79

89 Coolen, I. et al. (2005) Social learning in noncolonial insects? Curr. Biol. $15,1931-1935$

90 Tanner, D.A. and Visscher, P.K. (2008) Do honey bees average directions in the waggle dance to determine a flight direction? Behav. Ecol. Sociobiol. 62, 1891-1898

91 Farina, W.M. et al. (2012) Olfactory information transfer during recruitment in honey bees. In Honeybee Neurobiology and Behavior - A Tribute to Randolf Menzel (Galizia, C.G. et al., eds), pp. 89-101, Springer

92 Galef, B.G. et al. (2008) Social learning of food preferences in 'dissatisfied' and 'uncertain' Norway rats. Anim. Behav. 75, 631-637

93 Sen Sarma, M. et al. (2009) Transcriptomic profiling of central nervous system regions in three species of honey bee during dance communication behavior. PLoS ONE 4, e6408

94 Leadbeater, E. (2009) Social learning: what do Drosophila have to offer? Curr. Biol. 19, R378-R380 